\title{
Penetrating Scrotal Trauma: A Case Report and Brief Management with Literature Review
}

\section{Drew Jensen, Mehul S Patel and Stephen H Culp*}

Department of Urology, University of Virginia, USA

*Corresponding author: Stephen H Culp, Box 800422, Charlottesville, VA 22908, USA, Tel: 434-243-9325; Fax: 434-982-3652; E-mail: shc5e@virginia.edu

Rec Date: Jun 17, 2014; Acc Date: Aug 27, 2014; Pub Date: Aug 29, 2014

Copyright: (C) 2014 Jensen D, et al. This is an open-access article distributed under the terms of the Creative Commons Attribution License, which permits unrestricted use, distribution, and reproduction in any medium, provided the original author and source are credited.

\begin{abstract}
Penetrating scrotal trauma is an uncommon injury that is often secondary to civilian or combat violence. Much of the literature on the topic is from case reports, small retrospective series from civilian trauma centers, and reports from combat zones. In this manuscript, a case report involving self-inflicted penetrating scrotal trauma from our institution is presented. Following the case report, accepted management strategies and recent literature on the topic of penetrating scrotal trauma are reviewed. Briefly, current management strategies for penetrating scrotal injuries involve initial resuscitation and stabilization of the patient, followed by operative exploration, with the primary operative goals of hemostasis, debridement, and testicular salvage. Recent case series of penetrating scrotal trauma have shown rates of testicular salvage that vary between institutions, mechanism of injury, and setting (civilian vs military/combat).
\end{abstract}

Keywords: Penetrating scrotal trauma; Testicular salvage; Genital self-Mutilation

\section{Introduction}

Penetrating scrotal trauma is relatively rare. The location and structure of the scrotum serve to minimize any injury that occurs in many trauma scenarios. In fact, large, level I trauma centers may only see 3-4 cases of penetrating external male genitourinary trauma annually [1]. Although rare, penetrating scrotal trauma represents a medical emergency that emergency room physicians, traumatologists, and urologists must be able to assess and manage in a rapid and efficient manner.

\section{Case Presentation}

A 29-year-old male with chronic testicular pain and significant psychiatric and substance abuse history presented intoxicated to our emergency department with a self-inflicted scrotal laceration. He had been noncompliant with his prescribed psychiatric medications. The patient stated that his chronic testicular pain had become unbearable over the previous week, so he used a box-cutter to incise his scrotum and self-amputate both of his testicles. On initial exam, there was a large laceration on the base of his penis extending to his scrotum. His testicles were neither visualized nor palpable, and were not brought in by the patient. Brisk arterial bleeding was present from his spermatic vessels, which were subsequently clamped with hemostats. There was no blood present at his urethral meatus or any other injury apparent on physical exam. His vitals on presentation were BP 134/68 and HR 110; he was afebrile. Urinalysis was unremarkable. His initial laboratory work showed a hemoglobin and hematocrit of $15.1 \mathrm{~g} / \mathrm{dL}$ and 42.8, respectively. However, both of these values trended downward, and his hemoglobin was $10.4 \mathrm{~g} / \mathrm{dL}$ and hematocrit was 30.6 shortly after his initial evaluation. In addition, his lactic acid was elevated at $14.6 \mathrm{mmol} / \mathrm{L}$. The patient immediately received urologic evaluation and the patient was emergently taken to the operating room for surgical exploration and management of his scrotal injury. Immediately preoperatively, his vitals remained relatively stable and were BP 120/64, HR 96, and RR 18; he was still afebrile. General anesthesia with rapid-sequence intubation was used for anesthetic purposes.

After induction of anesthesia, the laceration was irrigated; the testes were absent. Hemostasis was achieved by ligating the spermatic cords with 0 -silk ties and 2-0 silk suture. Debridement of devitalized tissue was then performed, followed by pulse irrigation of the wound with a bacitracin-normal saline solution. Although suspicion for urethral injury was low, cystourethroscopy was performed and revealed no urethral or bladder injury. The laceration on the base of the penis was then closed with 4-0 Monocryl suture until it met the scrotum. The dartos fascia was closed with a running 3-0 Chromic stitch, and the scrotal skin was closed with interrupted 4-0 Monocryl stitches approximately every $1 \mathrm{~cm}$. The scrotum was then wrapped in gauze and Coban, and a scrotal support garment was placed. The patient tolerated the procedure well and was transferred to the postoperative care unit in stable condition. He was observed overnight and then admitted to the psychiatric service the following morning.

\section{Discussion}

The etiology of penetrating scrotal injuries is varied. They largely stem from violent acts, either self-inflicted or inflicted on others. In one case series from an urban trauma center, $94 \%$ (50/53) of isolated penetrating scrotal injuries were attributable to violent acts [1]. In the civilian population, the most common mechanisms of penetrating scrotal injury are gun-shot wounds and stab wounds, though animal bites and accidental trauma are prevalent as well [1-3]. As seen in our case, a small proportion of these scrotal injuries may be self-inflicted, especially in patients with a history of psychiatric illness, in chronic pain, or in patients identifying themselves as transgender [4]. It is also important to note that external genital injury is not uncommon among military personnel and civilians in combat zones. Recent reports from war zones in the Middle East have shown high rates of external 
genitourinary trauma, with a large proportion of these injuries representing penetrating scrotal trauma [5,6]. Regardless of the mechanism of injury, penetrating scrotal trauma requires immediate evaluation and management by urologic specialists.

For patients presenting with a penetrating scrotal injury, a prompt assessment by medical personnel is essential. As with all trauma patients, the first priority should be stabilization of vital signs and control of active bleeding. Afterwards, the initial evaluation should involve a thorough history, which should assess for the type of injury, the magnitude of injury, and any other contributing factors, such as intoxication or presence of psychotic symptoms. As in our case, selfinflicted genital trauma strongly suggests either intoxication or active psychosis, and should prompt concomitant psychiatric evaluation. Physical exam should evaluate and document scrotal lacerations and wounds, and assess for any compromise to the scrotal dartos fascia and any apparent damage to scrotal contents. Additionally, penetrating trauma to the scrotum often involves adjacent structures $[7,8]$. Thus, a comprehensive physical exam of the abdomen, pelvis, penis, perineum, thighs, and lower extremities looking for associated injury must be performed. A laboratory evaluation, including a complete blood count, urinalysis, and stool guaiac test should also be performed, which help to determine injury severity and will aid in identifying any associated injuries. In addition, the tetanus status of the patient must be obtained, and a tetanus booster should be given, if indicated, in addition to broad-spectrum antibiotics. In the case of scrotal trauma secondary to an animal bite, a rabies immunization should also be given if the rabies status of the animal is unknown or the animal cannot be isolated and observed.

In patients with an isolated penetrating scrotal injury, no imaging studies are recommended, and immediate operative exploration is indicated $[1,2,9,10]$. Numerous publications on penetrating scrotal trauma demonstrate that $>90 \%$ of patients presenting with penetrating scrotal trauma ultimately require operative scrotal exploration, regardless of mechanism of injury $[1,2,10]$. Furthermore, guideline statements from the European Association of Urology recommend that all penetrating injuries to the scrotum require surgical exploration [11]. In a minority of cases in which the scrotal injury is obviously superficial and the dartos fascia is uncompromised, non-operative management with scrotal ultrasound, local wound care, and observation can be attempted, with further management dictated by sonographic findings $[2,10]$.

The vast majority of patients with penetrating scrotal trauma will require surgical exploration of the scrotum. The goals of exploration are hemostasis, debridement of unviable tissue, and, in cases of testicular injury, testicular salvage. Testicular injury occurs in approximately $50 \%$ of all civilian penetrating scrotal trauma $[1,10]$. In cases where anatomically feasible, testicular salvage should take high priority, in order to preserve reproductive and hormonal function. Testicular salvage rates vary depending on the institution, the mechanism of injury, and the time from injury to presentation. Phonsombat et al. reported a testicular salvage rate of $75 \%$ with testicles injured via gun-shot wound to the scrotum, while only $23 \%$ of testicles injured via stab wound to the scrotum were salvageable; overall, $49 \%$ of injured testicles in this series were able to be salvaged [1]. Simhan et al. reported testicular injury in $48 \%$ of patients with gun-shot wounds to the scrotum, with a reported a testicular salvage rate of $52 \%$ among these injured testicles [10]. Waxman et al. reported an overall $74.4 \%$ testicular salvage rate among testicles injured via penetrating trauma in combat scenarios [6]. Although the goal is testicular salvage, not all testicles are able to be saved and are removed. In cases of complete testicular amputation, testicular replantation may be attempted, though successful replantation rarely occurs after 4-6 hours from time of amputation [12].

Post-operatively, most patients do well. Reported complication rates are relatively low, ranging from 2 to $7.7 \%$ among series at level I trauma centers $[1,10]$. Complications include abscess and hematoma formation which can be managed with drainage or evacuation. Selfinflicted injuries should prompt a psychiatric evaluation postoperatively. Finally, in cases of bilateral amputation (as in our case), or in cases of severe testicular injury where a bilateral orchiectomy is indicated, evaluation and management by an endocrinologist is warranted based on the future need for hormone replacement.

\section{Conclusion}

Penetrating scrotal trauma requires prompt medical evaluation and management. Although mechanisms of injury are varied, the vast majority of penetrating scrotal injuries will require surgical exploration with operative emphasis on hemostasis, debridement of unviable tissue, and testicular salvage. Testicular salvage rates display variability among institutions and mechanism of injury. However, if managed promptly and appropriately, testicular salvage is a realistic goal in many circumstances.

\section{References}

1. Phonsombat S, Master VA, McAninch JW (2008) Penetrating external genital trauma: a 30-year single institution experience. J Urol 180: 192-195.

2. Cline KJ, Mata JA, Venable DD, Eastham JA (1998) Penetrating trauma to the male external genitalia. J Trauma 44: 492-494.

3. Ferguson GG, Brandes SB (2007) Gunshot wound injury of the testis: the use of tunica vaginalis and polytetrafluoroethylene grafts for reconstruction. J Urol 178: 2462-2465.

4. Stunell H, Power RE, Floyd M Jr, Quinlan DM (2006) Genital selfmutilation. Int J Urol 13: 1358-1360.

5. Al-Azzawi IS, Koraitim MM2 (2014) Lower genitourinary trauma in modern warfare: the experience from civil violence in Iraq. Injury 45: 885-889.

6. Waxman S, Beekley A, Morey A, Soderdahl D (2009) Penetrating trauma to the external genitalia in Operation Iraqi Freedom. Int J Impot Res 21: 145-148.

7. Bertini JE Jr, Corriere JN Jr (1988) The etiology and management of genital injuries. J Trauma 28: 1278-1281.

8. Ferlise VJ, Haranto VH, Ankem MK, Barone JG (2002) Management of penetrating scrotal injury. Pediatr Emerg Care 18: 95-96.

9. Bandi G, Santucci RA (2004) Controversies in the management of male external genitourinary trauma. J Trauma 56: 1362-1370.

10. Simhan J, Rothman J, Canter D, Reyes JM, Jaffe WI, et al. (2012) Gunshot wounds to the scrotum: a large single-institutional 20-year experience. BJU Int 109: 1704-1707.

11. Summertom DJ, Djakovic N, Kitrey ND, Kuehhas F, Lumen N, et al. (2013) Guideline on urological trauma. European Association of Urology.

12. McAninch JW (1996) Traumatic and Reconstructive Urology (1stedtn) Saunders Publishing. 699-713. 